\title{
If your car was broken, would you take it to a garage that fixed less than 10 cars a year?
}

\author{
Moishe Liberman, MD, PhD
}

See related article on pages 2269-78.

The traditional definition of perioperative mortality is at 30 days postintervention. Numerous publications in various different disciplines have recently demonstrated that 30 day mortality rates do not sufficiently capture death related to the procedure in specific subsets of patients and causes of death. In this issue of the Journal, Pezzi and colleagues ${ }^{1}$ examined 114,905 patients who had undergone major pulmonary resection for lung cancer in 1233 hospitals from the US National Cancer Data Base over a 5-year period and looked at 30-day, conditional 90-day, and 90-day mortality, and their relationship to hospital volume.

In this cross-sectional study, the 90 -day mortality (5.4\%) was approximately double the 30 -day mortality $(2.8 \%)$. Low hospital volume for major pulmonary resection was significantly associated with increased 30-day, conditional 90-day, and 90-day mortality. Hospitals performing less than 30 resections per year had a more than $3 \%$ unadjusted 30 -day mortality compared with $1.7 \%$ in those performing more than 90 cases per year. This is not surprising. Regionalization of lung cancer care to high-volume centers ${ }^{2,3}$ and high-volume surgeons ${ }^{4}$ has been shown to decrease perioperative morality and even long-term mortality. The majority of studies looking at hospital and surgeon volume and mortality rates examined perioperative mortality using the 30day definition. An important point to keep in mind when reading the article is that high and low volume were defined using what most thoracic oncologists would consider very, very low volume $(<10$ and $<30$ cases per year, respectively). Nine percent of resections were performed in hospitals with an annual surgical volume of less than 10 cases per year, $45 \%$ of cases were performed in hospitals performing less than 30 cases per year, and the median annual volume was very low at 33 cases per year.

\footnotetext{
From the University of Montreal, Montreal, Quebec, Canada.

Disclosures: Author has nothing to disclose with regard to commercial support.

Received for publication Aug 22, 2014; accepted for publication Aug 22, 2014; available ahead of print Sept 26, 2014.

Address for reprints: Moishe Liberman, $\mathrm{MD}, \mathrm{PhD}$, Division of Thoracic Surgery, Centre Hospitalier de l'Université de Montréal, 1560 rue Sherbrooke Est, 8e CD - Pavillon Lachapelle, Bureau D-8051, Montréal, Québec, Canada H2L 4M1 (E-mail: moishe.liberman@umontreal.ca).

J Thorac Cardiovasc Surg 2014;148:2279

$0022-5223 / \$ 36.00$

Copyright (c) 2014 by The American Association for Thoracic Surgery

http://dx.doi.org/10.1016/j.jtcvs.2014.08.052
}

Superior mortality outcomes in lung cancer surgery are related not only to surgeon volume but also to hospital expertise, hospital resources, dedicated and specialized nurses, physiotherapists, respiratory technicians, specialized equipment, multidisciplinary oncology teams, surgeon training, specialized thoracic anesthesiologists, thoracic surgery intensive care expertise, teams of surgeons who are able to cover call and deal with complications 24 hours a day, 7 days a week, 365 days a year, and experienced house staff and fellow coverage..$^{5-7}$ These elements are difficult to isolate because of the complex interplay among them. To include all of these important elements in a hospital, a large volume of pulmonary resections are necessary to attract surgeons and allied health professionals and allow for a hospital or payer system to have a positive return on its investment.

So, if your car was broken, would you take it to a garage that fixed less than 10 cars a year? There is no question that the regionalization of the surgical care of lung cancer would be an effective way to improve patient outcomes and probably decrease costs. The question remains, is the regionalization of lung cancer care practical, feasible, and politically possible?

\section{References}

1. Pezzi CM, Mallin K, Mendez AS, Gay EG, Putnam JB. Ninety-day mortality after resection for lung cancer is nearly double 30-day mortality. J Thorac Cardiovasc Surg. 2014;148:2269-78.

2. Lüchtenborg M, Riaz SP, Coupland VH, Lim E, Jakobsen E, Krasnik M, et al. High procedure volume is strongly associated with improved survival after lung cancer surgery. J Clin Oncol. 2013;31:3141-6.

3. Bach PB, Cramer LD, Schrag D, Downey RJ, Gelfand SE, Begg CB. The influence of hospital volume on survival after resection for lung cancer. N Engl J Med. 2001; 345:181-8.

4. Falcoz PE, Puyraveau M, Rivera C, Bernard A, Massard G, Mauny F, et al. The impact of hospital and surgeon volume on the 30-day mortality of lung cancer surgery: a nation-based reappraisal. J Thorac Cardiovasc Surg. 2014;148:841-8.

5. Birkmeyer JD, Siewers AE, Finlayson EV, Stukel TA, Lucas FL, Batista I, et al Hospital volume and surgical mortality in the United States. $N$ Engl J Med. 2002;346:1128-37.

6. Birkmeyer JD, Sun Y, Wong SL, Stukel TA. Hospital volume and late survival after cancer surgery. Ann Surg. 2007;245:777-83

7. Cheung MC, Hamilton K, Sherman R, Byrne MM, Nguyen DM, Franceschi D, et al. Impact of teaching facility status and high-volume centers on outcomes for lung cancer resection: an examination of 13,469 surgical patients. Ann Surg Oncol. 2009;16:3-13. 